\title{
COMBATER A JURISPRUDÊNCIA DEFENSIVA COM O NOVO CPC: "YES, WE CAN!" OR CAN WE?
}

\section{TO FIGHT AGAINST THE DEFENSIVE JURISPRUDENCE WITH THE NEW CIVIL PROCEDURE CODE: YES, WE CAN! OR CAN WE?}

\author{
Rafael Ambrósio Gava ${ }^{1}$ \\ Janaina Gomes Garcia De Moraes ${ }^{2}$
}

\section{RESUMO}

Com o fim utilitarista de reduzir suas cargas de trabalho, os tribunais brasileiros têm cunhado vários entendimentos jurisprudenciais que acarretam restrições ilegítimas ao direito de recorrer, amesquinhando com isso o direito constitucional fundamental de acesso à justiça. Em que pese a existência de estudos a respeito dessa jurisprudência defensiva, ainda há poucos que a analisam à luz do novo Código de Processo Civil (Lei 13.105/2015), o qual está prestes a entrar em vigor. A proposta deste artigo é avaliar a aptidão do novo CPC para sanar esse vício judicante ou, ao menos, dificultar a sua ocorrência. Demonstrou-se, com base em pesquisa bibliográfica e mediante uma problematização dedutivo-argumentativa, que a nova lei processual contém uma série de previsões casuísticas e cláusulas gerais que podem ser usadas como instrumentos hábeis a refrear a defensividade jurisprudencial. Nada obstante, a concretização dos efeitos visados com a instituição desses enunciados legais dependerá, em grande parte, da maneira como eles serão interpretados e aplicados pelos operadores do direito.

Palavras-chave: Novo CPC, Lei 13105, Direito de recorrer, Jurisprudência, Defensiva

\begin{abstract}
In order to reduce their workloads, Brazilian Courts have been landing many precedents that lead to unwarranted restrictions to the right to appeal, thereby belittling the fundamental constitutional right to access to justice. Despite the existence of studies on this "defensive jurisprudence", there are still few who analyze it in the light of the new Civil Procedure Code (Law 13.105/2015), which is about to enter into force. This article aims to evaluate the suitability of the new CPC to remedy this adjudicative problem or at least minimize it. We demonstrated, based on literature and through a deductive argumentative reasoning, that the new procedural law contains a number of specific and general legal clauses which may be used as instruments able to curb the adjudicate "defensiveness. Nonetheless, the achievement of this goal will depend largely on how this legal clauses are to be interpreted and applied.
\end{abstract}

Keywords: New civil procedure code, Law 13105, Right to appeal, Defensive, Jurisprudence

\footnotetext{
${ }^{1}$ Mestrando em Direito Processual Civil pela Universidade Federal do Espírito Santo - UFES, Espírito Santo, (Brasil). E-mail: rafaelambrosiogava@yahoo.com.br

${ }^{2}$ Mestranda em Direito pela Universidade Federal do Espírito Santo - UFES, Espírito Santo, (Brasil). Auditora de controle externo no Tribunal de Contas do Estado do Espírito Santo, (Brasil). E-mail: janaggm@gmail.com
} 


\section{INTRODUÇÃO}

Afinal, o novo Código de Processo Civil é bom? Esta é uma pergunta que, na iminência se sua entrada em vigor, muitos se fazem e outros tantos se empenham em responder. Prova disso são os vários artigos científicos (BUENO, 2015a; CABRAL, 2015; MACHADO, 2015; MITIDIERO, 2015; NUNES, 2015; RODRIGUES, 2015; STRECK et al, 2015; THEODORO JÚNIOR, 2015) e livros (ALVIM; ALVIM; ASSIS, 2014; BUENO, 2015b; CHEIM JORGE, 2015; MARINONI; ARENHART; MITIDIERO, 2015; MEDINA, 2015; WAMBIER; DIDIER JR.; TALAMINI; DANTA, 2015) que dizem respeito à Lei 13.105/2015 - todos os quais, direta ou indiretamente, são impelidos pelo afã de responder a questão em comento ou, ao menos, a ela remetem.

Responder o questionamento proposto de modo adequado e suficientemente fundamentado em argumentos sólidos é tão desafiador quanto necessário. Desafiador, uma vez que pressupõe o conhecimento dos mais de mil artigos do novo código, dos assuntos que se prestam a disciplinar, dos problemas que levaram à sua formulação e dos demais diplomas normativos com que ele dialogará (dentre os quais a Constituição de 1988). Necessário, porque a boa interpretação/aplicação (GRAU, 2009) dos enunciados jurídico-normativos depende de uma avaliação crítica a respeito deles que viabilize não apenas a sua compreensão, mas também uma reflexão sobre os seus potenciais e a sua viabilidade para solucionar as questões sociais que o direito posto é chamado a enfrentar (AMARAL, 2014; NEVES, 1998, UNGER, 2004).

Ante a inviabilidade de em poucas páginas enfrentar satisfatoriamente o questionamento inicial em toda a sua amplitude, decotamos sua extensão, detendo-nos sobre um só assunto: "jurisprudência defensiva", isto é, restrições indevidas ao direito de recorrer (WAMBIER, 2005) que são impostas pelos tribunais (especialmente os superiores), mediante entendimentos jurisprudenciais (sumulados ou não) formulados com base em interpretações/aplicações inadequadas e canhestras - porque sem observância aos postulados da proporcionalidade e da razoabilidade (ÁVILA, 2014) - de enunciados legais e constitucionais, com o fim utilitarista de reduzir a carga de trabalho do Judiciário (AMARAL; SILVA, 2014; BARROS, 2008), amesquinhando o direito constitucional fundamental de acesso à justiça (MENDES; BRANCO, 2015). Avaliamos, pois, se o novo código é bom para fazer frente a tal prática. 
Elegemos este tema não só pela sua relevância e atualidade, mas também porque, a despeito dos estudos que vêm sendo feitos a seu respeito (CHEIM JORGE, 2013; CIUFFO, 2008; MOREIRA, 2006), ainda são poucos os que o abordam à luz do novo código, fazendo uma reflexão acerca da aptidão deste para sanar esse vício judicial ou dificultar a sua ocorrência. Esperamos, assim, contribuir para o debate.

Para concretizar os objetivos visados, lemos a Lei 13.105/2015 (novo Código de Processo Civil), bem como livros, artigos científicos, notícias e enunciados normativos (legais, constitucionais e jurisprudenciais) pertinentes. Em seguida, analisamos o material recolhido, lançando mão da problematização e do método dedutivo-argumentativo.

\section{A "DEFENSIVIDADE" E AS TÉCNICAS LEGISLATIVAS PARA REMEDIÁ-LA}

Iniciaremos este tópico definindo o termo "jurisprudência defensiva" e tecendo considerações semiológicas que dele decorrem. Em seguida, abordaremos duas técnicas legislativas das quais se pode lançar mão para enfrentá-la, a saber: a casuística e as cláusulas gerais. Ao fazê-lo, abordaremos suas potencialidades e limitações. Por fim, apontaremos aquela que, em nossa visão, é a melhor forma legislativa para combater esse vício judicante.

\subsection{DEFINIÇÃO DE “JURISPRUDÊNCIA DEFENSIVA”}

"Jurisprudência defensiva" é qualquer restrição ilegítima ao direito de recorrer imposta pelos tribunais, por meio de posicionamentos jurisprudenciais cunhados com base em interpretações/aplicações desproporcionais e não razoáveis de enunciados jurídico-normativos, com o fim de reduzir a carga de trabalho do Judiciário, dificultando o acesso à justiça. Essa definição, embora extensa, é útil para explicitar o conceito do termo, indicando os seus critérios de uso e, assim, viabilizando a conotação das decisões judiciais que os preencham. Dito de outro modo, "jurisprudência defensiva" é uma "classe de entendimentos jurisprudenciais" da qual farão parte todas as decisões que preencham os requisitos essenciais para pertencer a tal grupo, os quais são apontados na definição dada. As que, entretanto, deixarem de preencher tais requisitos não integrarão essa classe, não poderão a esta ser subsumidas (MOUSSALEM, 2006), ou seja, não serão espécies de "defensividade". 
Infere-se, mediante essas considerações semiológicas, que o conteúdo dessa classe é variável, de enorme amplitude e difícil denotação (GUIBOURG; GHIGLIANI; GUARINONI, 1993). Afinal, qualquer decisium que preencher os critérios de uso do termo, receberá tal epíteto. Não é possível, pois, conhecer ou antever aprioristicamente a totalidade dos entendimentos jurisprudenciais que cabem ou podem vir a caber nesse grupo. Além disso, a todo tempo é possível o abandono ou adoção de um particular posicionamento defensivo por parte deste ou daquele órgão judicante.

\subsection{A CASUÍSTICA}

Casuística é a "[...] configuração da hipótese legal (enquanto somatório dos pressupostos que condicionam a estatuição) que circunscreve particulares grupos de casos na sua especificidade própria” (ENGISCH, 2004, p. 228). Em outras palavras, é técnica legislativa por meio da qual se estabelece uma prescrição jurídico-normativa mediante concreção específica, ou seja, consiste na disciplina legal de um assunto via delimitação e definição jurídicas particulares de um grande número de eventos bem discriminados, com o intuito de evitar generalizações (ENGISCH, 1968).

$\mathrm{Na}$ medida em que opera com tipificações precisas, esse método tem o benefício de facilitar e ao mesmo tempo balizar o trabalho do intérprete/aplicador, assegurando maior grau de certeza quanto aos fatos e condutas que são ou não são abarcados por cada enunciado legal. Em contrapartida e justamente em função desse alto grau de precisão e especificidade, traz os malefícios da imutabilidade, da rigidez, da pretensão de completude e do anacronismo (MARTINS-COSTA, 2000).

Nesse sentir, é pouco eficaz combater a "defensividade" exclusivamente por meio do casuísmo legislativo, visto que essa técnica opera com tipificações que, além de rígidas, atua no nível da "espécie", não no do "gênero" em si. Com efeito, na medida em que a classe de entendimentos jurisprudenciais defensivos apresenta conteúdo altamente variável, criar um enunciado normativo que enfrenta especificamente os precedentes " $x$ " e " $y$ ", não será capaz de afrontar os posicionamentos "w" e " $z$ ", tampouco mostrar-se-á hábil a evitar o surgimento de outros tantos ou a solucioná-los. Assim, pretender resolver o problema em tela apenas mediante 
o ataque às espécies é como tentar matar uma hidra (monstro mitológico grego) cortando-lhe as cabeças uma a uma (POUZADOUX, 2001).

Não estamos dizendo que a tipificação específica é impassível de ensejar qualquer sorte de resultado profícuo. Afinal, é óbvio que a criação de um enunciado legislativo que faz frente ao precedente defensivo " $\mathrm{x}$ " terá o efeito proveitoso de, com grandes precisão e segurança, impedir (ou ao menos dificultar) a sua perpetuação. Queremos apenas ressaltar que, a despeito da eficácia desse método para solucionar questões pontuais, o seu potencial resolutivo é de baixa amplitude, em função dos motivos já expostos. Dessarte, depositar todas as esperanças somente nessa técnica é superestimar a clarividência do Legislativo e subestimar a criatividade de um Judiciário que tem se mostrado marcadamente utilitarista, pragmático, "consequencialista" e formalista no que tange à admissibilidade recursal. Valer-se somente dela significa assumir o risco da inflexibilidade e rápida defasagem legislativa.

\subsection{AS CLÁUSULAS GERAIS}

A técnica de legislar por meio de cláusulas gerais - que não se confundem com princípios (ÁVILA, 2014; GUASTINI, 2005), nem com termos indeterminados (ENGISCH, 2004) - consiste na formulação de enunciados normativos de molduras intencionalmente vagas e abertas, é dizer, dotados de ampla extensão semântica. Trata-se, portanto, de um método que se opõe ao casuísmo, na medida em que enseja a criação de dispositivos legais cujos conteúdos não são previamente dados, e que só podem ser preenchidos mediante interpretações/aplicações feitas à luz de casos concretos (LIMA NETO, 2008).

Este método viabiliza a abertura do direito posto ao dinamismo da vida social, visto possibilitar a incorporação de máximas, diretivas e princípios extrajurídicos, bem como de direitos, deveres e institutos ainda não positivados. Ademais, facilita o diálogo entre os veículos normativos. Propicia, assim, a contínua "ressistematização" jurídica (MARTINS-COSTA, 1998).

Por conseguinte, a positivação de cláusulas gerais permite o enfrentamento da jurisprudência defensiva de modo abrangente (focando-se no gênero em si e nas suas características definidoras, não nas espécies que o compõem), assegurando maiores mobilidade 
e dimensão aplicativa. Além disso, envolve menor risco de defasagem legal. Isso porque possibilita aos intérpretes/aplicadores a construção, à luz dos casos concretos, de uma série de normas pertinentes ao combate das variadas formas de manifestação desse problema.

De outro lado, a vagueza inerente a esse método legislativo faz com que seja difícil estabelecer os limites de interpretação/aplicação dos enunciados assim formulados. Em função disso, enseja certo nível de incerteza (Pelo menos até que os entendimentos doutrinários e jurisprudenciais sejam firmados a respeito deles). E embora as cláusulas gerais não consistam num apelo à discricionariedade (GODINHO, 2000), é inegável que podem dar margem a “decisionismos”, arbitrariedades e excessivo subjetivismo (AZEVEDO, 1999).

Com efeito, o alto grau de indefinição de enunciados vagos cunhados com o fito de fazer frente à "defensividade" jurisprudencial permite que tudo seja por eles abarcado, mas também possibilita que nada o seja. Precisamente por isso, muitos juristas - cansados de serem negativamente surpreendidos por sucessivas decisões judiciais arbitrárias (SILVA, 2012) duvidam da boa vontade de parte dos julgadores para interpretar/aplicar, com a abrangência almejada, cláusulas gerais positivadas com o fim de corrigir esse distúrbio.

\subsection{A MELHOR OPÇÃO LEGISLATIVA}

Assentamos que o gênero "jurisprudência defensiva" tem conteúdo específico aprioristicamente indeterminado (embora determinável à luz do caso concreto), variante e que é (re)dimensionado à medida em que entendimentos jurisprudenciais são firmados e alterados.

Vimos que, embora a casuística dê parâmetros de interpretação/aplicação muito seguros e precisos, não é possível, a conta da mutabilidade característica daquele gênero, delimitar e abarcar de todas as espécies que nele cabem de maneira definitiva e em rol casuístico de tipos legais, o qual está sujeito à inevitável defasagem, tornando-se insuficiente para alcançar o fim a que se destina: remediar a "defensividade" de modo abrangente.

De outra parte, asseveramos que, a despeito do recurso às cláusulas gerais propiciar a abarcadura, a mobilidade e o dinamismo necessários ao enfrentamento dessa mácula, dá margem a subjetivismos, dubiedades e arbitrariedades. 
Os dilemas decorrentes do uso exclusivo de um ou de outro método legislativo em tela podem ser contornados mediante a mescla de ambos (LIMA NETO, 2008) - os quais podem ser utilizados de modo complementar, a fim de que um possa remediar os problemas desencadeados pelo outro (MARTINS-COSTA, 1998). Nos dizeres de Karl Engisch, uma “[...] combinação particularmente aconselhável de método casuístico e cláusula geral é a do chamado método exemplificativo [...]" (2004, p. 231) por meio do qual esta última é associada a uma enumeração casuística de exemplos que a ela se relacionam, pautando a interpretação/aplicação do enunciado vago e evidenciando que não se está diante de uma enunciação exaustiva.

Ante o exposto, a opção legislativa com maior aptidão para combater a jurisprudência defensiva é aquela que combina a positivação de cláusulas gerais referentes a esse gênero de entendimentos jurisprudenciais e/ou aos seus requisitos definidores com a estipulação casuística de tipos voltados ao enfrentamento dos seus exemplos já conhecidos (não só os exemplos que ainda são encampados, mas também aqueles que, embora estejam atualmente superados, já foram perfilhados e, por isso, podem a qualquer momento ser reavivados).

\section{ANÁLISE DO NOVO CÓDIGO DE PROCESSO CIVIL (LEI 13.105/2015)}

Demonstraremos, neste tópico, que o novo CPC contém um considerável número de dispositivos (pelo menos inegavelmente maior do que o CPC/73) que foram casuisticamente cunhados com a finalidade precípua de fazer frente às espécies mais recorrentes e conhecidas de "defensividade" jurisprudencial. Além disso, contém cláusulas gerais que, se bem interpretadas/aplicadas, podem mostrar-se hábeis ao combate dessa mácula de modo abrangente.

Uma espécie de jurisprudência defensiva bastante conhecida e criticada pela doutrina (FARIA, 2010) é aquela segundo a qual os recursos especial e extraordinário interpostos por advogado sem procuração nos autos é inexistente - v.g. o verbete $\mathrm{n}^{\circ} 115$ da súmula da jurisprudência do STJ e o ARE 654690 AgR, do Plenário do STF (BRASIL, 1994, 2014a). Ela acarreta inexplicável e desrazoável restrição de aplicabilidade do artigo 13 do CPC/1973 na instância recursal extraordinária (BRASIL, 1973). 
Com o intuito de rebatê-la, o artigo 76 do novo CPC (equivalente ao artigo 13 do CPC/73) faz menção expressa a "tribunal superior" em seu $\S 2^{\circ}$, não deixando dúvidas quanto ao seu cabimento também nos recursos excepcionais (BRASIL, 2015).

O $\S 4^{\circ}$ do artigo 218 do novo CPC, a seu turno, estabelece que “[...] será considerado tempestivo o ato praticado antes do termo inicial do prazo" (BRASIL, 2015). Ataca, assim, o entendimento jurisprudencial (SICA, 2007) segundo o qual os recursos interpostos antes das partes serem intimadas do decisum impugnado são intempestivos - e.g. o ARE $638700 \mathrm{AgR}$ ED/MG, do Plenário do STF, e o EDcl na SEC 3.660/GB, da Corte Especial do STJ (BRASIL, 2010a, 2012a).

Orientação defensiva muito similar à mencionada no parágrafo anterior é exigência de o recorrente ratificar recurso por si interposto após o julgamento de embargos de declaração aposto pela parte contrária, mesmo que este último seja inadmitido, desprovido ou não modifique substancialmente a parte do julgamento anterior impugnada pelo recurso cuja ratificação se exige - v.g. o enunciado 418 da súmula da jurisprudência do STJ e o AR 1.332 AgR-AgR/SP, do Plenário do STF (BRASIL, 2010b, 2014b). Este entendimento, censurável por deturpar o princípio da complementariedade (NERY JÚNIOR, 1997), será solapado pelo artigo $1.024, \S \S 4^{\circ}$ e $5^{\circ}$, do novo CPC, na medida em que tais dispositivos o contrariam de modo cabal.

É igualmente digno de nota o artigo 941, § 3º pelo qual “[ ...] o voto vencido será necessariamente declarado e considerado parte integrante do acórdão para todos os fins legais, inclusive de prequestionamento" (BRASIL, 2015). Em complementação, o artigo 1.025 dispõe que " [...] consideram-se incluídos no acórdão os elementos que o embargante pleiteou para fins de prequestionamento, ainda que os embargos de declaração sejam inadmitidos ou rejeitados, caso o tribunal superior considere existentes erro, omissão, contradição ou obscuridade" (BRASIL, 2015). Em conjunto, esses dois enunciados facilitam a configuração do prequestionamento, indo na contramão da rígida jurisprudência que os tribunais superiores têm a respeito desse requisito de admissibilidade recursal - p.ex., citamos os verbetes 211 e 320 da súmula da jurisprudência do STJ (BRASIL, 1998, 2005a), os quais têm sido qualificados como defensivos (WAMBIER, 2005).

Também é bastante censurada pela doutrina (CHEIM JORGE, 2013) a jurisprudência dos tribunais superiores que - apequenando o princípio da fungibilidade recursal - não admite 
a conversão de recurso extraordinário em recurso especial, e vice-versa, em hipótese alguma. O AgRg no ARESP 418.395/RS, proferido pela Quarta Turma do STJ, e a decisão monocrática prolatada pela Ministra Rosa Weber no RE 855.798/SP (BRASIL, 2013, 2014c) são representativos desse malsinado posicionamento jurisprudencial. Cedendo aos anseios doutrinários, os congressistas fizeram constar no novo código os artigos 1.032 e 1.033, que expressamente prescrevem tal providência.

Outro exemplo de jurisprudência defensiva apontado pela doutrina (FREIRE; CASTRO, 2013) é a aplicação da pena de deserção nos casos em que, a despeito das partes terem efetuado o pagamento do preparo e do porte de remessa e retorno de forma correta, integral e tempestiva, se esqueceram de comprovar o recolhimento no ato da interposição do recurso. Por outras palavras: exclui-se a possibilidade de, após a data do protocolo, demonstrar que essas taxas foram pagas nos valor, modo e prazo prescritos em lei - e.g., o AgRg nos EDcl nos EAREsp 193.798/BA, da Corte Especial do STJ, e o RE 606.376 ED-EDv, do Plenário do STF (BRASIL, 2014d, 2014e). Mencione-se, ainda, entendimento já perfilhado pelo STJ no sentido de que a ausência do número do processo na guia de recolhimento ou o preenchimento incorreto desta também ensejariam a deserção - v.g. AgRg nos EREsp 1.129.680/RJ e REsp 655.418/PR (BRASIL, 2005b, 2012b). Para minar essas posições, o artigo 1.007, $\S 2^{\circ}$ e $4^{\circ}-7^{\circ}$, do novo código prevê expressamente as possibilidades de pagamento, complementação, comprovação e regularização do preparo e do porte de remessa de retorno após a data do protocolo.

Leia-se, ainda, o teor do artigo 489, $\S 1^{\circ}$, I, II, V e VI, do novo CPC:

$\S 1^{\circ}$ Não se considera fundamentada qualquer decisão judicial, seja ela interlocutória, sentença ou acórdão, que:

I - se limitar à indicação, à reprodução ou à paráfrase de ato normativo, sem explicar sua relação com a causa ou a questão decidida;

II - empregar conceitos jurídicos indeterminados, sem explicar o motivo concreto de sua incidência no caso; $[\ldots]$.

V - se limitar a invocar precedente ou enunciado de súmula, sem identificar seus fundamentos determinantes nem demonstrar que o caso sob julgamento se ajusta àqueles fundamentos;

VI - deixar de seguir enunciado de súmula, jurisprudência ou precedente invocado pela parte, sem demonstrar a existência de distinção no caso em julgamento ou a superação do entendimento. (BRASIL, 2015). 
As prescrições acima são complementadas pelo art. $1.029, \S 2^{\circ}$, do mesmo diploma, segundo o qual "[...] quando o recurso [especial ou extraordinário] estiver fundado em dissídio jurisprudencial, é vedado ao tribunal inadmiti-lo com base em fundamento genérico de que as circunstâncias fáticas são diferentes, sem demonstrar a existência da distinção" (BRASIL, 2015). Erige-se, assim, barreira contra as decisões defensivas que se valem indiscriminadamente de enunciados sumulares, artigos de lei, jargões ou termos de grande amplitude semântica e alto grau de indeterminação, com o objetivo específico de impedir o conhecimento de recursos e sem explicar, de modo satisfatoriamente fundamentado e preciso, o porquê de eles serem hábeis a justificar a inadmissibilidade recursal em cada caso (FARINA, 2012) - v.g. enunciado 284 da súmula da jurisprudência do STF, o REsp 1.274.551/RS, proferido pela $2^{\text {a }}$ Turma do STJ, e o AgRg no Ag 815.186/RJ, prolatado pela $1^{\text {a }}$ Turma do STJ (BRASIL, 1963, 2007, 2011).

$\mathrm{O}$ art. 188 do novo código (equivalente ao artigo 154 do CPC/73) dispõe que "[...] os atos e os termos processuais independem de forma determinada, salvo quando a lei expressamente a exigir, considerando-se válidos os que, realizados de outro modo, lhe preencham a finalidade essencial" (BRASIL, 2015). Esse dispositivo está situado na "Seção I - Dos atos em geral”, do "Capítulo I - Da forma dos atos processuais", do "Título I - Da forma, do tempo e do lugar dos atos processuais", do "Livro IV - Dos atos processuais, da "Parte Geral" do novo código. É aplicável, portanto, a todos os atos processuais, inclusive aqueles inerentes à interposição, processamento, admissibilidade e julgamento dos recursos em geral.

O dispositivo mencionado no parágrafo anterior tem íntima relação com os artigos 932, parágrafo único, e 938, $\S \S 1^{\circ}-3^{\circ}$, do novo CPC, que, tratando especificamente da ordem dos processos e dos meios de impugnação de decisões judiciais nos tribunais, contrapõem-se ao formalismo nos seguintes termos:

Art. 932. Incumbe ao relator: [...].

Parágrafo único. Antes de considerar inadmissível o recurso, o relator concederá o prazo de cinco dias ao recorrente para que seja sanado vício ou complementada a documentação exigível.

Art. 938. [...].

$\S 1^{\circ}$ Constatada a ocorrência de vício sanável, inclusive aquele que possa ser conhecido de ofício, o relator determinará a realização ou a renovação do ato processual, no próprio tribunal ou em primeiro grau, intimadas as partes; 
cumprida a diligência, sempre que possível prosseguirá no julgamento do recurso.

$\S 2^{\circ}$ Reconhecida a necessidade de produção de prova, o relator converterá o julgamento em diligência, que se realizará no tribunal ou em instância inferior, decidindo-se o recurso após a conclusão da instrução.

$\S 3^{\circ}$ Quando não determinadas pelo relator, as providências indicadas nos $\S \S$ $1^{\circ}$ e $2^{\circ}$ poderão ser determinadas pelo órgão competente para julgamento do recurso. (BRASIL, 2015).

Não bastassem os três últimos artigos transcritos, os congressistas fizeram questão de cunhar outros mandamentos antiformalistas: um especificamente concernente ao agravo e à formação de seu instrumento; outro referente ao conhecimento de recurso extraordinário e de recurso especial. Vejamos, respectivamente:

Art. 1017. A petição de agravo de instrumento será instruída: [...].

$\S 3^{\circ} \mathrm{Na}$ falta da cópia de qualquer peça ou no caso de algum outro vício que comprometa a admissibilidade do agravo de instrumento, deve o relator aplicar o disposto no art. 932, parágrafo único.

Art. 1029. O recurso extraordinário e o recurso especial, nos casos previstos na Constituição Federal, serão interpostos perante o presidente ou o vice-presidente do tribunal recorrido, em petições distintas que conterão: $[\ldots]$.

$\S 3^{\circ} \mathrm{O}$ Supremo Tribunal Federal ou o Superior Tribunal de Justiça poderá desconsiderar vício formal de recurso tempestivo ou determinar sua correção, desde que não o repute grave. (BRASIL, 2015).

Estamos diante de inequívocas prescrições normativas contrárias ao apreço pelas formas como um fim em si mesmo. Se levadas a sério (DWORKIN, 2007) pela comunidade de intérpretes/aplicadores do direito (em especial por aqueles que laboram no Judiciário), podem ajudar a combater a "defensividade jurisprudencial" de modo abrangente. Afinal, o apego excessivo às formas - dissociado das finalidades que as motivam e as justificam (OLIVEIRA, 2006) - se faz presente em várias espécies de entendimentos jurisprudenciais defensivos, dentre os quais alguns dos que foram mencionados acima.

Também não podemos deixar de mencionar os artigos $3^{\circ}$, caput, $4^{\circ}, 5^{\circ}$ e $6^{\circ}$ do novo CPC. Estes artigos, lidos em conjunto e à luz dos incisos XXXV, LIV e LXXVIII do artigo $5^{\circ}$ da Constituição (BRASIL, 1988), impõem a todos os sujeitos processuais (sobretudo os julgadores) o dever de adotar posturas condizentes com a boa-fé objetiva e de cooperar para que se obtenha uma justa e efetiva resolução do mérito em tempo razoável, sendo ilegítimas 
as condutas que, de qualquer modo, tenham o efeito de retardar, dificultar ou excluir da apreciação jurisdicional lesão ou ameaça a direito. É importante destacar que estes três dispositivos são verdadeiras cláusulas gerais e estão localizados no "Capítulo I - Das normas fundamentais do processo civil", do "Título único - Das normas fundamentais e da aplicação das normas processuais", do "Livro I - Das normas processuais civis", da "Parte geral" do novo código (BRASIL, 2015). Nesse sentir, são vetores que devem pautar não apenas a interpretação/aplicação de todo enunciado normativo afeto ao processo civil, mas também as posturas dos julgadores em todas as fases processuais, inclusive a recursal. Os aludidos artigos impõem aos magistrados o dever de, sempre que possível, apreciar o mérito das questões que lhes são apresentadas, inclusive na instância recursal. São, portanto, cláusulas que se contrapõem aos mais vários artifícios criados arbitrariamente pelos órgãos judicantes com o fim utilitarista de reduzir a sua carga de trabalho mediante a inadmissão de recursos.

Ainda no capítulo das normas fundamentais do processo civil, os congressistas fizeram constar o artigo $8^{\circ}$, que impõe ao "juiz", o dever de interpretar/aplicar os enunciados jurídicos segundo os "fins sociais" e as "exigências do bem comum", sempre velando pela "proporcionalidade", pela "razoabilidade", pela "legalidade" e pela "eficiência" (BRASIL, 2015). Teceremos, nos próximos parágrafos, comentários respeitantes ao aludido dispositivo.

Às vezes o óbvio precisa ser dito. Nossa primeira observação, portanto, é a seguinte: este artigo não encerra mera sugestão, nem tem função meramente retórica ou decorativa. Tratase de enunciado linguístico cunhado e usado com função prescritiva, ou seja, para deontologicamente vincular todos que se sujeitam ao direito brasileiro posto (CARVALHO, 2015).

Nossa segunda observação, não menos elementar que a primeira, é a de que o termo “juiz” presente no dispositivo em análise não se refere apenas ao julgador singular de primeira instância, mas sim ao "Estado-Juiz", ou seja, aos julgadores em geral, qualquer que seja a instância ou órgão jurisdicional em que oficiem. O dispositivo em comento abarca e vincula até mesmo os juízes leigos, os árbitros e os ministros do Supremo.

A terceira observação volta-se às expressões "fins sociais" e "exigências do bem comum". Não obstante esses termos ostentem grande carga emotiva e vasta amplitude semântica, há limites interpretativos. Na medida em que esses vocábulos compõem uma frase cunhada com função prescritiva e que fazem parte de um sistema de direito positivo estruturado 
a partir e com base na Constituição, é forçoso reconhecer que as únicas compreensões juridicamente aceitáveis daquelas expressões são as que se pautam e têm espeque nesta última (STRECK, 2005, 2008). Por via de consequência, o art. $8^{\circ}$ impõe que os julgadores balizem a interpretação/aplicação dos enunciados jurídicos pelos "fins sociais" e "exigências do bem comum" impostos pela Constituição de 1988 e pelas leis que viabilizam a realização dos mandamentos constitucionais, formando verdadeiro "direito constitucional concretizado" (CANOTILHO, 2011). Essa conclusão se reforça pelo teor do art. $1^{\circ}$ do novo CPC, que expressamente remete o operador do direito à Constituição.

A quarta observação diz respeito aos termos "proporcionalidade", "razoabilidade" e "legalidade". A menção expressa aos dois primeiros vocábulos torna evidente a necessidade de os julgadores pautarem a interpretação/aplicação dos veículos normativos pelos aludidos postulados. Esperamos que eles sejam usados criteriosamente e que não sejam encarados (tal qual têm frequentemente sido) como "palavras mágicas" hábeis a dar aparências de legitimidade e tecnicismo a toda sorte de arbitrariedade e desconsideração oportunista de dispositivos legais (ÁVILA, 2014). O fato de o termo "legalidade" seguir-se imediatamente aos dois primeiros, aliás, não parece ter sido mero acaso, mas sim um meio de evidenciar que a alusão aos postulados em comento não deve ser encarada como uma possibilidade de o julgador escolher livremente se quer ou não seguir esta ou aquela prescrição legislativa. Afinal, a legalidade dirige-se também aos que exercem função jurisdicional.

A quinta observação refere-se à expressão "eficiência" presente no artigo $8^{\circ}$ do novo CPC. É importante ter em mente que velar pela eficiência envolve não apenas primar pela quantidade, mas também pela qualidade de despachos, decisões, sentenças e acórdãos proferidos e pela aptidão deles para assegurar a justa e efetiva resolução das questões colocadas perante o Judiciário. Se um "julgador X", por exemplo, profere 100 sentenças, das quais somente 10 resolveram o mérito do processo, é fácil perceber que ele foi menos eficiente do que o "julgador Y" que proferiu 60 sentenças, todas estas com efetiva, integral e satisfatória solução das controvérsias subjacentes. Afinal, nestes 60 casos, há menor probabilidade de as partes terem que novamente se socorrer do Judiciário pelos mesmos motivos ou por razões a eles conexos. O termo "eficiência”, portanto, deve ser visto não só na dimensão individual de cada processo, mas também na dimensão macro. Significa, em última análise, uma exigência de bom funcionamento e boa performance da função jurisdicional desempenhada pelo 
Judiciário. Trata-se de assegurar aos jurisdicionados, em tempo razoável, o fácil e franco acesso a uma ordem jurídica justa e efetiva (WAMBIER, 2013).

Como decorrência dessas cinco observações, temos que o artigo $8^{\circ}$ se contrapõe à "defensividade" jurisprudencial de modo abarcante. Explicamos. A Constituição de 1988 assegura o acesso amplo (facilitado e com todos os recursos e meios de impugnação previstos no ordenamento jurídico) a uma prestação jurisdicional apta a viabilizar a prolação, em tempo razoável, de decisão capaz de efetivamente resolver o mérito das questões colocadas perante o Judiciário. Nesse sentir, qualquer restrição ilegítima ao direito de recorrer imposta por órgãos jurisdicionais, por meio de entendimentos cunhados com base em interpretações/aplicações canhestras de enunciados jurídico-normativos, com o fim de reduzir a carga de trabalho do Judiciário, dificultam o acesso à justiça, são desproporcionais, não razoáveis e ineficientes, deixam de atender os fins e as exigências constitucionais e contrariam a legalidade.

Além dos dispositivos já mencionados, convém transcrever os artigos 926, caput, e $927, \S \S 2^{\circ}-4^{\circ}$, do novo código. Vejamos:

Art. 926. Os tribunais devem uniformizar sua jurisprudência e mantê-la estável, íntegra e coerente. [...]

Art. 927. Os juízes e os tribunais observarão: [...].

$\S 2^{\circ}$ A alteração de tese jurídica adotada em enunciado de súmula ou em julgamento de casos repetitivos poderá ser precedida de audiências públicas e da participação de pessoas, órgãos ou entidades que possam contribuir para a rediscussão da tese.

$\S 3^{\circ} \mathrm{Na}$ hipótese de alteração de jurisprudência dominante do Supremo Tribunal Federal e dos tribunais superiores ou daquela oriunda de julgamento de casos repetitivos, pode haver modulação dos efeitos da alteração no interesse social e no da segurança jurídica.

$\S 4^{\circ}$ A modificação de enunciado de súmula, de jurisprudência pacificada ou da tese adotada em julgamento de casos repetitivos observará a necessidade de fundamentação adequada e específica, considerando os princípios da segurança jurídica, da proteção da confiança e da isonomia. (BRASIL, 2015).

A reiteração de precedentes (mormente pelos tribunais superiores) gera legítimas expectativas de continuidade decisória, passando a nortear comportamentos dos demais órgãos judiciais e de diversos setores e agentes sociais. Nesse jaez, alterações constantes e inadvertidas de jurisprudência podem causar surpresas, injustiças, quebra de confiança (LUHMANN, 1996) e instabilidade jurídica. Não há dúvidas, portanto, de que é salutar a exigência expressa de 
estabilidade jurisprudencial, bem como a existência de previsões legais que remetem logicamente às técnicas de "prospective overruling", "prospective-prospective overruling" e "pure-prospective overruling" e "sinalizing" (CARRAZZA; FERRAZ JUNIOR; NERY JUNIOR, 2009; DERZI, 2009; EISENBERG, 1998; GONÇALVES, 2012; LARENZ, 1997; LEDERMAN, 2004; MARINONI, 2010，2011; MARKMAN, 2010; NELSON, 2001; PECZENIK, 2009; SUMMERS, 1997).

A estabilidade, entretanto, não é bastante para evitar arbítrios judiciais, razão pela qual o novo CPC também impõe ao Judiciário os deveres de uniformidade, coerência e integridade jurisprudenciais. Nesse sentir, além de terem que velar pela estabilidade, os julgadores devem zelar para que casos iguais (ou melhor, "similares", já que nenhum caso é exatamente igual) sejam decididos do mesmo modo (é dizer, igualmente, na medida de suas igualdades relevantes). Mais do que isso, impõe-se que os órgãos judicantes enxerguem o sistema jurídico como um conjunto unificado e coerente de enunciados normativos entre si concatenados e estruturados a partir da Constituição. Exige-se que a fundamentação das decisões seja assentada em argumentações racionais, pautadas pela Constituição e pelos demais veículos normativos que viabilizam a concretização dela (STRECK, 2014).

Por via de consequência, as exigências de estabilidade, uniformidade, coerência e integridade jurisprudenciais são hábeis a assegurar a integridade do ordenamento jurídico, a força normativa da Constituição e a refrear "decisionismos" e arbitrariedades judiciais. Nesse sentir, se levados a sério, os artigos 926, caput, e 927, §§ $2^{\circ}-4^{\circ}$, do novo código têm inegável aptidão para fazer frente à "defensividade" jurisprudencial de modo abarcante, tendo em vista o caráter arbitrário e "decisionista" dessa malsinada prática judicante.

Todos os dispositivos do novo CPC até agora mencionados são dignos de elogios, visto que (cada um a seu modo) têm o mérito de viabilizar o enfrentamento da jurisprudência defensiva de maneira específica ou abrangente. Infelizmente, entretanto, o $\S 6^{\circ}$ do art. 1.003 do novo CPC dispõe que "[...] o recorrente comprovará a ocorrência de feriado local no ato de interposição do recurso" (BRASIL, 2015). Convém destacar que o aludido dispositivo está topograficamente situado no "Capítulo I - Das disposições gerais”, do “Título II - Dos recursos", do "Livro III - Dos processos nos tribunais e dos meios de impugnação das decisões judiciais", da "Parte especial". Nesse sentir, mais do que ratificar essa espécie de jurisprudência defensiva (OLIVEIRA JUNIOR, 2013), os congressistas a agravaram. Afinal, essa exigência 
poderá passar a ser aplicável a todos os recursos (em vista da localização topográfica do aludido dispositivo), ao passo que atualmente ela só tem sido feita (e com certos temperamentos) em relação aos recursos excepcionais - v.g. o RE 626.358 AgR/MG, proferido pelo Plenário do STF, e o AgRg no AREsp 137.141/SE, prolatado pela Corte Especial do STJ (BRASIL, 2012c, 2012d).

\section{CONCLUSÃO}

Demonstramos, assim, que o novo código lança mão da estipulação casuística de tipos voltados a refrear os exemplos clássicos e já conhecidos de "defensividade" - não só os que ainda são encampados, mas também aqueles que, embora estejam atualmente superados, já foram perfilhados e, por isso, podem a qualquer momento ser reavivados. Com isso, fornece parâmetros consideravelmente seguros e precisos para o ataque legislativo de tais espécies de entendimento jurisprudencial.

Ao lado daqueles tipos, e em complementação a eles, a Lei 13.105/2015 contém cláusulas gerais que viabilizam o combate da jurisprudência defensiva de modo abrangente (focando-se no gênero em si e nas suas características definidoras, não nas espécies que o compõem) e asseguram maiores mobilidade e amplitude aplicativa, bem como menor risco de defasagem legislativa, visto que possibilita aos intérpretes/aplicadores a construção, à luz dos casos concretos, de uma série de normas pertinentes ao combate das mais diversas formas de manifestação desse vício.

$\mathrm{Na}$ medida em que combina as técnicas supramencionadas, de modo que uma complemente a outra e remedeie os problemas operativos a ela inerentes, o novo código trilha aquela que, em nossa visão, é a melhor via para o combate legislativo da jurisprudência defensiva (em perspectivas específica e genérica).

Logo, no que tange ao fornecimento de instrumentos jurídicos destinados ao enfrentamento desse problema social, o novo CPC é inegavelmente melhor do que o CPC/73. Assim, em resposta ao questionamento proposto, podemos afirmar que, embora a Lei 13.105/2015 não seja perfeita, no geral ela é boa para refrear esse distúrbio judicial. 
Sem prejuízo das colocações feitas, é imperioso fazer uma importante observação. Embora as leis processuais atualmente postas (dentre elas o $\mathrm{CPC} / 73$ ) não se ocupem da "defensividade jurisprudencial" de modo tão minudente quanto o novo código, é inegável que se os seus enunciados fossem lidos à luz da Constituição de 1988 e bem interpretados/aplicados, viabilizariam a formulação de inúmeras normas hábeis a solver esse problema. Por que, então, isso não se verifica? E, mais importante, será que isso seguirá ocorrendo a despeito da entrada em vigor do novo CPC?

Tenha-se em mente que a criação de uma "norma jurídica" depende da conduta criativa de um operador do direito que se debruce sobre o texto positivado e o compreenda à luz de determinado contexto. Acrescente-se, ainda, que a ordem jurídica não se realiza do modo efetivo sem que as normas gerais e abstratas ganhem concreção e individuação. E isso só ocorre mediante a prática, pelos juristas, de "atos ponentes" por meio dos quais são construídas as normas individuais e concretas, levando em conta as molduras traçadas pelas normas abstratas e gerais. Em termos mais simples: a realização do direito não se dá de modo mágico ou fantástico, depende necessariamente da atividade humana - não apenas para fins de construção das normas (desde as gerais e abstratas até as individuais e concretas), mas também para que sejam faticamente implementados (dependendo do caso, mediante de sanção institucionalizada) os efeitos normativamente prescritos (BOBBIO, 2008, CARVALHO, 2015).

Nesse sentir, de que adiantaria ter leis perfeitas, se estas não fossem concretizadas a contento por operadores do direito efetivamente comprometidos com a sua efetiva realização, com o seu máximo aproveitamento? De nada ou muito pouco adiantaria. Não há dúvidas, pois, quanto à importância das condutas e posturas assumidas pelos juristas para que o sistema jurídico não se resuma a um emaranhado de palavras constantes em documentos oficiais e para que seja "socialmente eficaz". Irretocável, portanto, a fala de Júlio César Pompeu, para quem "leis são como sonhos: se realizam na medida em que cremos nelas" (2006).

Queremos, assim, ponderar que a postulação legislativa, por si só, não é suficiente para resolver os problemas sociais que demandam enfrentamento jurídico. É necessário que a lei venha acompanhada de posturas ativas de juristas que "levem o direito a sério" (DWORKIN, 2007) e que estejam preparados para interpretar/aplicar os enunciados legais de modo a obter o maior proveito possível de cada um deles, segundo os fins constitucionalmente fixadas. 
É ilusão pensar que a positivação de um novo código de processo civil por si só (por melhor que seja seu texto) será capaz de acabar com a “defensividade jurisprudencial” ou tornála menos pujante e frequente. Para que isso ocorra, é necessário que os julgadores abandonando o fim utilitarista de reduzir a qualquer custo a sua carga de trabalho comprometam-se a verdadeiramente implementar as previsões constitucionais e legais de acesso à justiça (inclusive às instâncias recursais); é indispensável que sejam alteradas as posturas e atitudes interpretativas/aplicativas dos juristas - não só dos que exercem função jurisdicional, mas também de todos aqueles que estão em posição de fiscalizar e chamar à responsabilidade os julgadores que deliberadamente impõem ilegítimas restrições ao acesso à justiça e ao direito de recorrer.

Assim, tão importante quanto indagar se o novo código de processo civil é bom, é perguntar se estamos preparados para (e dispostos a) implementá-lo a contento, ou seja, em conformidade com os ditames constitucionais e os reclames sociais.

\section{REFERÊECIAS}

ALVIM, Arruda; ALVIM, Eduardo Arruda; ASSIS, Araken de. Comentários ao Código de Processo Civil: Com Apontamentos Sobre o Projeto do Novo CPC. 3. ed. rev. ampl. São Paulo: RT, 2014.

AMARAL, Ana Cláudia Corrêa Zuin Mattos do; SILVA, Fernando Moreira Freitas da. A jurisprudência defensiva dos tribunais superiores: a doutrina utilitarista mais viva que nunca. In: LAMY, Eduardo de Avelar (Coord.); MARIN, Jeferson Dytz (Coord.); VILLATORE, Marco Andônio César (Coord.). Processo e jurisdição II (Recurso eletrônico on-line). Florianópolis: CONPEDI, 2014, p. 40-58. Disponível em: <http://www.publicadireito.com.br/publicacao/ufsc/livro.php?gt=198>. Acesso em: 9 ago. 2015.

AMARAL, Francisco. Direito civil: introdução. 8. ed. ver. mod. e aum. Rio de Janeiro: Renovar, 2014.

ÁVILA, Humberto. Teoria dos Princípios: da definição à aplicação dos princípios jurídicos. 15. ed. ampl. atual. São Paulo: Malheiros, 2014. 
AZEVEDO, Antônio Junqueira de. O direito pós-moderno e a codificação. Revista da Faculdade de Direito da USP, São Paulo, v. 94, p. 3-12, 1999.

BARROS, Humberto Gomes de. Discurso de posse do Ministro Humberto Gomes de Barros no cargo de Presidente do STJ. BDJur, Brasília, DF, 28 abr. 2008. Disponível em: <http://bdjur.stj.jus.br/xmlui/bitstream/handle/2011/16933/Discurso_Posse_Gomes\%20de\%20 Barros.pdf?sequence=1>. Acesso em: 9 ago. 2015.

BOBBIO, Norberto. Teoria geral do direito. 2. ed. São Paulo: Martins Fontes, 2008. BRASIL. Congresso Nacional. Lei 13.105, de 16 de março de 2015, Brasília. Disponível em: < http://www.planalto.gov.br/ccivil_03/_Ato2015-2018/2015/Lei/L13105.htm>. Acesso em: 9 ago. 2015.

Constituição (1988). Constituição [da] República Federativa do Brasil. Brasília: Senado Federal, 1988.

Lei $n^{\circ}$ 5.869, de 11 de janeiro de 1973. Diário Oficial [da] República Federativa do

Brasil, Brasília, 17 jan. 1973. Disponível em: <http://www.planalto.gov.br/ccivil_03/leis/15869compilada.htm>. Acesso em: 9 ago. 2015.

Superior Tribunal de Justiça. EDcl na SEC 3.660/GB. Ari Giongo e DEVCOT S/A. Relator: Arnaldo Esteves Lima. Brasília, 3 fev. 2010a. Acórdão eletrônico Dje 8 mar. 2010. Disponível em: $<$ https://ww2.stj.jus.br/processo/revista/documento/mediado/?componente=ITA\&sequencial= 940964\&num_registro=200802182824\&data=20100308\&formato=PDF>. Acesso em: 9 ago. 2015.

AgRg no Ag 815186/RJ. Baden Brasil S/A e Município do Rio de Janeiro.

Relator: Luiz Fux. Brasília, 6 mar. 2007. Dje 2 abr. 2007. Disponível em: $<$ https://ww2.stj.jus.br/processo/revista/documento/mediado/?componente=ITA\&sequencial= 677141\&num_registro=200602053309\&data=20070402\&formato=PDF $>$. Acesso em: 9 ago. 2015.

AgRg no AREsp 137.141/SE. NORGRAF Produtos Gráficos Ltda e Banco do Brasil S/A. Relator: Antônio Carlos Ferreira. Brasília, 19 set. 2012. Dje 15 out. 2012d. Disponível em: 
$<$ https://ww2.stj.jus.br/processo/revista/documento/mediado/?componente=ITA\&sequencial= 1179335\&num_registro=201200126420\&data=20121015\&formato=PDF $>$. Acesso em: 9 ago. 2015.

AgRg no AREsp 418.395/RS. Fundação Universidade de Caxias do Sul e Pâmela Boeira Dalzochio. Relatora: Maria Isabel Gallotti. Brasília, 19 nov. 2013. Acórdão eletrônico Dje $10 \quad$ dez. $2013 . \quad$ Disponível em: $<$ https://ww2.stj.jus.br/processo/revista/documento/mediado/?componente=ITA\&sequencial= 1281737\&num_registro=201303585444\&data=20131210\&formato=PDF $>$. Acesso em: 9 ago. 2015 .

AgRg nos EDcl nos EAREsp 193.798/BA. Marilu Ribeiro Viana e Instituto Nacional do Seguro Social. Relator: Jorge Mussi. Brasília, 6 ago. 2014. Dje 15 ago. 2014d. Disponível em: $<$ https://ww2.stj.jus.br/processo/revista/documento/mediado/?componente=ITA\&sequencial= 1335603\&num_registro=201302828272\&data=20140815\&formato=PDF $>$. Acesso em: 9 ago. 2015 .

AgRg nos EREsp 1129680/RJ. Companhia de Desenvolvimento do Sahy e Seaside Arquitetura Engenharia Construções Comércio e Indústria Ltda. Relator: Castro Meira. Brasília, 3 out. 2012. Dje 10 out. 2012b. Disponível em: $<$ https://ww2.stj.jus.br/processo/revista/documento/mediado/?componente=ITA\&sequencial= $1183685 \&$ num_registro $=201201625757 \&$ data $=20121010 \&$ formato=PDF $>$. Acesso em: 9 ago. 2015.

. REsp 655.418/PR. Sindicato dos Transportadores Rodoviários Autônomos de Bens no Estado do Paraná e Altamir de Jesus Santos e outros. Relator: Castro Meira. Brasília, 3 fev. 2005. Dje 30 mai. 2005b. Disponível em: $<$ https://ww2.stj.jus.br/processo/revista/documento/mediado/?componente=ITA\&sequencial= 522939\&num_registro=200400546574\&data=20050530\&formato=PDF $>$. Acesso em: 9 ago. 2015.

REsp 1274551/RS. Serviço Autônomo Municipal de Água e Esgoto de Brusque e Fazenda Nacional. Relator: Luiz Fux. Brasília, 11 out. 2011. Dje 20 out. 2011. 
Disponível

em:

$<$ https://ww2.stj.jus.br/processo/revista/documento/mediado/?componente=ITA\&sequencial= 1095853\&num_registro=201102063021\&data=20111020\&formato=PDF $>$. Acesso em: 9 ago. 2015 .

Súmula 115. Corte Especial, Brasília, 27 out. 1994. DJe 07 nov. 1994.

Disponível em: <http://www.stj.jus.br/SCON/>. Acesso em: 9 ago. 2015.

Súmula 211. Corte Especial, Brasília, 1 jul. 1998. DJe 3 ago. 1998. Disponível em: <http://www.stj.jus.br/SCON/>. Acesso em: 9 ago. 2015.

. Superior Tribunal de Justiça. Súmula 320. Corte Especial, Brasília, 5 out. 2005a. DJe

18 out. 2005. Disponível em: <http://www.stj.jus.br/SCON/>. Acesso em: 9 ago. 2015.

Súmula 418. Corte Especial, Brasília, 3 mar. 2010. DJe 11 mar. $2010 b$. Disponível em: <http://www.stj.jus.br/SCON/>. Acesso em: 9 ago. 2015.

Supremo Tribunal Federal. AR 1332 AgR-AgR/SP. Roberto Correale e Carlos Magalhães Realizações Imobiliárias S/A. Relatora: Cármen Lúcia. Brasília, 1 ago. 2014. Acórdão eletrônico DJe-159, Divulgado 18 ago. 2014, publicado 19 ago. 2014b. Disponível em: <http://redir.stf.jus.br/paginadorpub/paginador.jsp?docTP=TP\&docID=6534606>. Acesso em: 9 ago. 2015.

ARE 638700 AgR-ED/MG. Daniel Bernardes Vidigal Martins e Município de Ipatinga. Relator: Ayres Britto (Presidente). Brasília, 27 jun. 2012a. Acórdão eletrônico DJe-178, divulgado 10 set. 2012, publicado 11 set. 2012. Disponível em: <http://redir.stf.jus.br/paginadorpub/paginador.jsp?docTP=TP\&docID=2709883>. Acesso em: 9 ago. 2015.

ARE 654690 AgR/SP . Banco Bradesco S/A e Francisco Carlos Dadona.

Relator: Ricardo Lewandowski (Presidente). Brasília, 28 ago. 2014a. Acórdão eletrônico DJe-190, divulgado 29 set. 2014, publicado 30 set. 2014. Disponível em: $<$ http://redir.stf.jus.br/paginadorpub/paginador.jsp?docTP=TP\&docID=6826619>. Acesso em: 9 ago. 2015. 
. Decisão monocrática proferida no RE 855798/SP. Município de Santo André e Maria Cecilia Martinelli Werner. Relatora: Rosa Weber. Brasília, 14 dez. 2014. Processo eletrônico DJe-249, divulgado 17 dez. 2014, publicado 18 dez. 2014c. Disponível em: $<$ http://www.stf.jus.br/portal/processo/verProcessoAndamento.asp?numero $=855798 \&$ classe $=$ RE\&codigoClasse $=0 \&$ origem $=J U R \&$ recurso $=0 \&$ tipoJulgamento $=M>$. Acesso em: 9 ago. 2015.

. RE 606376 ED-EDv. Maria Sirlei Mallmann e Estado do Rio Grande do Sul. Relatora: Cármen Lúcia. Brasília, 19 nov. 2014e. Acórdão eletrônico DJe-250, divulgado 18 dez. 2014, publicado 19 dez. 2014. Disponível em: $<$ http://redir.stf.jus.br/paginadorpub/paginador.jsp?docTP=TP\&docID=7517772>. Acesso em: 9 ago. 2015.

RE 626358 AgR/MG. Fiat Auto Trading S.A. e Ezequiel Dutra de Oliveira. Relator: Cezar Peluso (Presidente). Brasília, 22 mar. 2012. Acórdão eletrônico DJe-166, divulgado 22 ago. 2012, publicado 23 ago. 2012c. Disponível em: $<$ http://redir.stf.jus.br/paginadorpub/paginador.jsp?docTP=TP\&docID=2613070>. Acesso em: 9 ago. 2015.

Súmula 284. Brasília, 13 dez. 1963. Disponível em:

<http://www.stf.jus.br/portal/jurisprudencia/listarJurisprudencia.asp?s1=\%28\%28284\%2ENU $\mathrm{ME} \% 2 \mathrm{E} \% 29 \% 29+\mathrm{NAO}+\mathrm{S} \% 2 \mathrm{EFLSV} \% 2 \mathrm{E} \&$ base=baseSumulas\&url=http://tinyurl.com/lgeew 9x>. Acesso em: 9 ago. 2015.

BUENO, Cassio Scarpinella. (In)devido processo legislativo e o novo código de processo civil. Revista do advogado, v. 35, n. 126, p. 39-46, maio 2015a.

Novo código de processo civil: anotado. São Paulo: Saraiva, 2015b.

CABRAL, Trícia Navarro Xavier. Convenções em matéria processual. RePro, n. 241, p. 489517, mar. 2015.

CANOTILHO, José Joaquim Gomes. Direito constitucional e teoria da constituição. 7. ed. Coimbra: Almedina, 2011. 
CARRAZZA, Roque Antônio; FERRAZ JUNIOR, Tércio Sampaio; NERY JUNIOR, Nelson. Efeito ex nunc e as decisões do STJ. Barueri: Manole, 2009.

CARVALHO, Paulo de Barros. Direito tributário, linguagem e método. 6. ed. rev. ampl. São Paulo: Noeses, 2015.

CHEIM JORGE, Flávio. Requisitos de admissibilidade dos recursos: entre a relativização e as restrições indevidas (jurisprudência defensiva). In: OLIVEIRA, Bruno Silveira de et al. (Coord.). Recursos e a razoável duração do processo. Brasília: Gazeta Jurídica, 2013, p. 173-201.

- Teoria geral dos recursos cíveis. 7. ed. rev. atual. e ampl. São Paulo: RT, 2015.CIUFFO, Diogo Carneiro. Os requisitos de admissibilidade dos recursos especial e extraordinário e a sua ilegítima utilização como filtros recursais. RePro, São Paulo, v. 106, p. 205-232, 2008.

DERZI, Misabel Abreu Machado. Modificações da jurisprudência no direito tributário. São Paulo: Noeses, 2009.

DWORKIN, Ronald. Levando os direitos a sério. 2. ed. São Paulo: Martins Fontes, 2007. EISENBERG, Melvin. The nature of the common law. Cambridge: Harvard University Press, 1998.

ENGISCH, Karl. Introdução ao pensamento jurídico. 9. ed. Lisboa: Fundação Calouste Gulbenkian, 2004.

La idea de concreción en el derecho y en la ciencia juridica actuales. 2. ed. Pamplona: Universidad de Navarra, 1968.

FARIA, Márcio Carvalho. O acesso à justiça e a jurisprudência defensiva dos tribunais superiores. Revista do Instituto dos Advogados de Minas Gerais, Belho Horizonte, v. 16, p. 371-388, 2010.

FARINA, Fernanda Mercier Querido. Jurisprudência defensiva e a função dos tribunais superiores. RePro, São Paulo, v. 209, p. 105-131, jul. 2012. 
FREIRE, Alexandre et al. (Org.). Novas Tendências do Processo Civil: Estudos sobre o Projeto do Novo Código de Processo Civil, v. 1-3. Salvador: Juspodivm, 2014.

FREIRE, Alexandre Reis Siqueira; CASTRO, Marcelo Soares. O juízo de admissibilidade do recurso extraordinário no projeto do novo código de processo civil brasileiro. In: LOCOHAMA, Celso Hiroshi (Coord.); SALDANHA, Jânia Maria Lopes (Coord.). Processo e jurisdição [Recurso eletrônico on-line]. Curitiba: CONPEDI, 2013, p. 371-389. Disponível em: <http://www.publicadireito.com.br/publicacao/unicuritiba/livro.php?gt=97>. Acesso em: 9 ago. 2015.

GODINHO, André. Codificação e as cláusulas gerais. Revista Trimestral de Direito Civil, Rio de Janeiro, ano 1, v. 2, p. 3-25, arb./jun. 2000.

GONÇALVES, Diego da Silva. O sistema de precedentes como garantidor da segurança jurídica, da previsibilidade e estabilidade das decisões judiciais. Processos Coletivos, Porto Alegre, v. 3, n. 3, set. 2012. Disponível em: <http://www.processoscoletivos.net/doutrina/36volume-3-numero-3-trimestre-01-07-2012-a-30-09-2012/1006-o-sistema-de-precedentescomo-garantidor-da-seguranca-juridica-da-previsibilidade-e-estabilidade-das-decisoesjudiciais>. Acesso em: 9 ago. 2015.

GRAU, Eros Roberto. Ensaio e discurso sobre a interpretação/aplicação do direito. 5. ed. rev. ampl. São Paulo: Malheiros, 2009.

GUASTINI, Riccardo. Das fontes às normas. São Paulo: Quartier Latin, 2005.

GUIBOURG, Ricado A.; GHIGLIANI, Alejandro M.; GUARINONI, Ricardo, V. Introducción al conocimiento científico. Buenos Aires: Eudeba, 1993.

LARENZ, Karl. Metodologia da ciência do direito. 3. ed. Lisboa: Calouste Gulbenkian, 1997.

LEDERMAN, Howard Yale. Judicial overruling. Time for a new general rule. Michigan Bar Jornal, Lansing, v. 83, n. 9, p. 22-24, set. 2004. Disponível em: <http://www.michbar.org/journal/pdf/pdf4article740.pdf>. Acesso em: 9 ago. 2015.

LIMA NETO, Francisco Vieira. O direito de não sofrer discriminação genética: uma nova expressão dos direitos da personalidade. Rio de Janeiro: Lúmen Juris, 2008. 
LUHMANN, Niklas. Confianza. Barcelona: Antrophos, 1996.

MACHADO, Marcelo Pacheco. Reformas no recurso de apelação: como a Itália escolheu enfrentar seus problemas e como o Brasil não. RePro, São Paulo, v. 243, p. 505-524, mai. 2015.

MARINONI, Luiz Guilherme. Eficácia temporal da revogação da jurisprudência consolidada dos tribunais superiores. Revista do TST, Brasília, v. 77, n. 3, p. 223-248, jul./set. 2011. Disponível em: <http://www.tst.jus.br/documents/1295387/42812205-635c-4fe5-9c338586713c7d32>. Acesso em: 9 ago. 2015.

Precedentes obrigatórios. São Paulo: RT, 2010.

MARINONI, Luiz Guilherme; ARENHART, Sérgio Cruz; MITIDIERO, Daniel. O novo processo civil. São Paulo: RT, 2015.

MARKMAN, Stephen. Originalism and stare decisis. Harvard Journal of Law \& Public Policy, Cambridge, v. 34, n. 1, p. 111-120, winter 2010. Disponível em: <http://www.harvardjlpp.com/wp-content/uploads/2013/10/MarkmanFinal.pdf>. Acesso em: 9 ago. 2015.

MARTINS-COSTA, Judith. A boa-fé no direito privado: sistema e tópica no processo obrigacional. São Paulo: RT, 2000.

O direito privado como um sistema em construção: as cláusulas gerais no projeto do código civil brasileiro. Revista de Informação Legislativa, Brasília, v. 139, p. 5-22, 1998.

MEDINA, José Miguel Garcia. Novo código de processo civil: comentado. 3. ed. São Paulo: RT, 2015.

MENDES, Gilmar Ferreira; BRANCO, Paulo Gustavo Gonet. Curso de direito constitucional. 10. ed. rev. atual. São Paulo:Saraiva, 2015.

MITIDIERO, Daniel. A colaboração como norma fundamental do novo processo civil brasileiro. Revista do advogado, v. 35, n. 126, p. 47-52, maio 2015.

MOREIRA, José Carlos Barbosa. Restrições ilegítimas ao conhecimento dos recursos. Revista da Escola Nacional da Magistratura, Brasília, v. 1, p. 38-52, 2006. 
MOUSSALLEM, Tárek Moysés. Fontes no direito tributário. 2. ed. São Paulo: Noeses, 2006.

NELSON, Caleb. Stare decisis and demonstrably erroneous precedents. Virginia Law Review, Richmond, v. 87, n. 1, p. 1-84, mar. 2001. Disponível em: <http://www.law.virginia.edu/pdf/faculty/hein/nelson/87va_1_rev1_2001.pdf>. Acesso em: 9 ago. 2015 .

NERY JÚNIOR, Nelson. Princípios fundamentais: teoria geral dos recursos. 4. ed. rev. e ampl. São Paulo: RT, 1997.

NEVES, António Castanheira. Entre o "legislador", a "sociedade" e o "juiz" ou entre "sistema", "função" e "problema": os modelos actualmente alternativos da realização jurisdicional do direito. Boletim da Faculdade de direito da Universidade de Coimbra, Coimbra, v. LXXIV [separata], p. 1-44, 1998.

NUNES, Dierle. A função contrafática do direito e o novo CPC. RePro, v. 35, n. 126, p. 5357, maio 2015.

OLIVEIRA, Carlos Alberto Alvaro de. O formalismo-valorativo no confronto com o formalismo excessivo. RePro, São Paulo, v. 137, p. 7-32, 2006.

OLIVEIRA JUNIOR, Zulmar Duarte de et al. A jurisprudência defensiva ainda pulsa no novo CPC. Consultor Jurídico, São Paulo, 6 set. 2013. Disponível em: <http://www.conjur.com.br/2013-set-06/jurisprudencia-defensiva-ainda-pulsa-codigoprocesso-civil>. Acesso em: 9 ago. 2015.

PECZENIK, Aleksander. On law and reason. 2nd. ed. New York: Springer-Verlag, 2009.

POMPEU, Júlio César. A importância dos princípios fundamentais face à nova hermenêutica constitucional. In: I Simpósio da Academia Brasileira de Direitos Humanos. Interpretação e Hermenêutica Constitucional: A importância dos princípios fundamentais face à nova hermenêutica constitucional. Vitória, 19 jul. 2006.

POUZADOUX, Claude. Contos e lendas da mitologia grega. São Paulo: Companhia das Leiras, 2001. 
RODRIGUES, Marcelo Abelha. O novo CPC e a tutela jurisdicional executiva (parte 1). RePro, São Paulo, v. 244, p. 85-152, jun. 2015.

THEODORO JÚNIOR, Humberto. Estabilização da demanda no novo Código de Processo Civil. RePro, São Paulo, v. 244, p. 195-208, jun. 2015.

SICA, Heitor Vitor Mendonça. Recurso intempestivo por prematuridade? In: NERY JR, Nelson (Org.); WAMBIER, Teresa Arruda Alvim (Org.). Aspectos polêmicos e atuais dos recursos cíveis. São Paulo: Revista dos Tribunais, 2007, v. 11, p. 134-144.

SILVA, Ticiano Alves e. Jurisprudência banana boat. RePro, São Paulo, v. 209, p. 289-292, jul. 2012.

STRECK, Lenio Luiz. Decisionismo e Discricionariedade judicial em tempos póspositivistas: o solipsismo hermenêutico e os obstáculos à concretização da constituição no Brasil. In: NUNES, António José Avelãs (Coord.); COUTINHO, Jacinto Nelson de Miranda (Coord.). O direito e o futuro - o futuro do direito. Coimbra: Almedina, 2008, p. 91-116.

Diferença (ontológica) entre texto e norma: afastando o fantasma do relativismo.

Revista da Faculdade de Direito da Universidade de Lisboa, v. XLVI, n. 1, p. 55-86, 2005. O novo CPC terá mecanismos para combater decisionismos e arbitrariedades? Consultor Jurídico, São Paulo, 18 dez. 2014. Disponível em: <http://www.conjur.com.br/2014-dez-18/senso-incomum-cpc-mecanismos-combaterdecisionismos-arbitrariedades>. Acesso em: 9 ago. 2015.

STRECK, Lênio Luiz, et al. O "bom litigante" - Riscos da moralização do processo pelo dever de cooperação do novo CPC. Revista brasileira de direito processual, v. 23, n. 90, p. 339354, abril/junho 2015.

SUMMERS, Robert. Precedent in the United States (New York State). Interpreting precedents: a comparative study. London: Dartmouth, 1997.

UNGER, Roberto Mangabeira. O Direito e o Futuro da Democracia. São Paulo: Boitempo, 2004. 
WAMBIER, Teresa Arruda Alvim. O CPC projetado, os recursos e o maior rendimento do processo. In: OLIVEIRA, Bruno Silveira de et al. (Coord.). Recursos e a razoável duração do processo. Brasília: Gazeta Jurídica, 2013, p. 475-485.

. Restrições indevidas ao direito de recorrer. RePro, São Paulo, v. 130, p. 249-250, dez. 2005.

WAMBIER, Teresa Arruda Alvim; DIDIER JR., Fredie; TALAMINI, Eduardo; DANTAS, Bruno (Coord.). Breves comentários ao código de processo civil. São Paulo: RT, 2015. 